\title{
An update on anticancer drug development and delivery targeting carbonic anhydrase IX
}

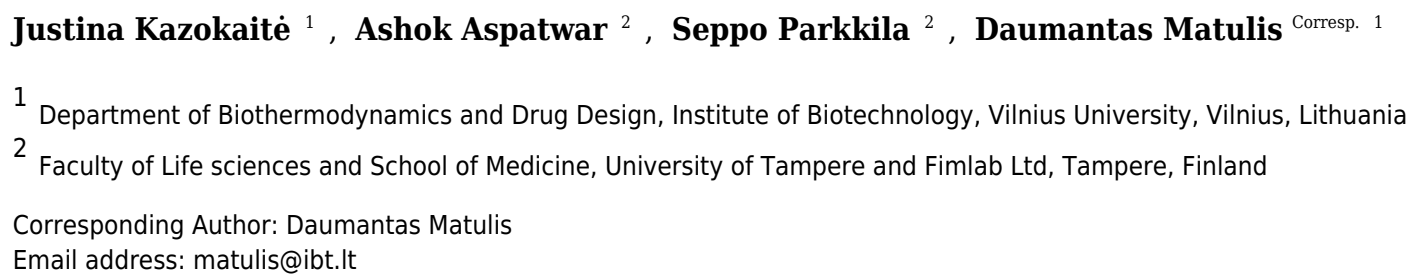

The expression of carbonic anhydrase (CA) IX is up-regulated in many types of solid tumors in humans under hypoxic and acidic microenvironment. Inhibition of CA IX enzymatic activity with selective inhibitors, antibodies or labeled probes has been shown to reverse the acidic environment of solid tumors and reduce the tumor growth establishing the significant role of CA IX in tumorigenesis. Thus, the development of potent antitumor drugs targeting CA IX with minimal toxic effects is important for the targetspecific tumor therapy. Recently, several promising antitumor agents against CA IX have been developed to treat certain types of cancers in combination with radiation and chemotherapy. Here we review the inhibition of CA IX by small molecule compounds and monoclonal antibodies. The methods of enzymatic assays, biophysical methods, animal models including zebrafish and Xenopus oocytes, and techniques of diagnostic imaging to detect hypoxic tumors using CA IX-targeted conjugates are discussed with the aim to overview the recent progress related to novel therapeutic agents that target CA IX in hypoxic tumors. 


\section{An update on anticancer drug development and delivery 3 targeting carbonic anhydrase IX}

4

5 IJustina Kazokaite ${ }^{l}$, ${ }^{\top}$ Ashok Aspatwar ${ }^{2}$, Seppo Parkkila ${ }^{2}$, Daumantas Matulis ${ }^{1, *}$

6

$7{ }^{1}$ Department of Biothermodynamics and Drug Design, Institute of Biotechnology, Vilnius

8 University, Vilnius, Lithuania

$9{ }^{2}$ Faculty of Life sciences and School of Medicine, University of Tampere and Fimlab Ltd.,

10 Tampere, Finland

11 Contributed equally

12

13 Corresponding author:

14 Daumantas Matulis ${ }^{1}$

15 Email address: matulis@ibt.1t, daumantas.matulis@bti.vu.1t 
17 Abstract:

The expression of carbonic anhydrase (CA) IX is up-regulated in many types of solid tumors in humans under hypoxic and acidic microenvironment. Inhibition of CA IX enzymatic activity with selective inhibitors, antibodies or labeled probes has been shown to reverse the acidic environment of solid tumors and reduce the tumor growth establishing the significant role of CA IX in tumorigenesis. Thus, the development of potent antitumor drugs targeting CA IX with minimal toxic effects is important for the target-specific tumor therapy. Recently, several promising antitumor agents against CA IX have been developed to treat certain types of cancers in combination with radiation and chemotherapy. Here we review the inhibition of CA IX by small molecule compounds and monoclonal antibodies. The methods of enzymatic assays, biophysical methods, animal models including zebrafish and Xenopus oocytes, and techniques of diagnostic imaging to detect hypoxic tumors using CA IX-targeted conjugates are discussed with the aim to overview the recent progress related to novel therapeutic agents that target CA IX in hypoxic tumors.

\section{INTRODUCTION}

Recent advances in cancer therapy show that hypoxia is the major contributor to tumor development $(1,2)$. The poor and chaotic tumor angiogenesis leads to the insufficient oxygen and nutrient supply which drastically affects the cellular metabolism (3). Due to the up-regulated glycolysis, tumor cells produce increased amounts of lactate and protons. As a consequence of mTORC1\&2 mediated functional and transcriptional activation of c-Myc, tumor cells tend to metabolize glucose preferably via glycolysis rather than oxidative phosphorylation despite sufficient levels of oxygen. This phenomenon is known as Warburg effect $(4,5)$. The resultant hypoxic and acidic extracellular milieu significantly increases the resistance of cancer cells to chemotherapy and radiotherapy as well as promotes invasiveness and metastasis $(6,7)$.

Hypoxia stimulates crucial pathways, one of which is implemented by the activation of the heterodimeric hypoxia-inducible factor (HIF) (8). This hypoxia-induced transcriptional program is important for tumor cells to survive harsh conditions. There are many downstream-target genes of HIF which encode proteins such as adhesion molecules (9), matrix metalloproteinases (10), chemokine receptors (11), growth factors (12), differentiation proteins (13), glycolytic enzymes (14), lactate transporters (15), and ion transporters (16). Some HIF-regulated proteins have been shown to be hypoxia-related anticancer targets and possess therapeutic applications (17). Thus, HIF is critically essential for cancer cells to survive and metastasize in the hostile tumor environment due to the HIF-dependent activation of oncogenes and inactivation of tumor suppressor genes.

As a consequence of HIF-mediated transcriptional response to tumor hypoxia, the intracellular 
$55 \mathrm{pH}\left(\mathrm{pH}_{\mathrm{i}}\right)$ is lower than the extracellular $\mathrm{pH}\left(\mathrm{pH}_{\mathrm{e}}\right)$, which is 7 .4. Pathologically $\mathrm{pH}_{\mathrm{i}}$ is higher than

56

57

58

59

60

61

62

63

64

65

66

67

68

69

70

71

72

73

74

75

76

77

78

79

80

81

82

83

84

85

86

87

88

89

90

91

92

93

$\mathrm{pH}_{\mathrm{e}}$, which is $6.7-7.1(18,19)$. This phenomenon of extracellular acidification under hypoxic conditions is created by HIF-dependent induction of proteins, such as transmembrane enzymes, ion pumps, and transporters. They export lactate and protons and import bicarbonate ions to optimize the tumor progression. Among key $\mathrm{pH}$-regulators are $\mathrm{V}$-ATPase, $\mathrm{Na}^{+} / \mathrm{H}^{+}$exchanger (NHE), monocarboxylate transporters (MCTs) and carbonic anhydrase (CA) IX.

There are seven evolutionarily distinct CA gene families: $\alpha-, \beta-, \gamma-, \delta-, \zeta-\eta-$, and $\theta$-CAs $(20-25)$. In humans, there are only $15 \alpha$-CA isoforms, of which 12 are catalytically active and exhibit diverse enzymatic activity, various cellular distribution and physiological functions (26). Being a member of $\alpha$-CA isoforms in human body, CA IX is a transmembrane homodimer, which catalyzes the reversible hydration of carbon dioxide to bicarbonate and proton outside the cell. The intracellular $\mathrm{pH}$ of cancer cells is regulated by the export of lactate and protons and on the import of bicarbonate ions generated by the hydration of $\mathrm{CO}_{2}$. The acidic metabolites accumulate pericellularly because of the ineffective tumor vasculature and extracellular acidosis. To reduce changes of intracellular $\mathrm{pH}$, the bicarbonate is transported into the cell through the bicarbonate transport metabolon composed of CA IX and bicarbonate transporters. Thereby CA IX is important for cancer cell proliferation because of the participation in both processes: the extracellular acidification and the intracellular alkalinization $(24,27)$.

CA IX is relevant not only for the cancer cell survival but also to several other biological processes such as the maintenance of cancer stem cell (CSC) function, migration, and invasion. Cell migration depends on the formation of lamellipodia which have been shown to be partially produced by activation of CA IX and its interaction with bicarbonate transporters (28). In addition, acidosis under hypoxic conditions activates proteolytic enzymes, which degrade the extracellular matrix and promote metastasis formation. Thus, CA IX targeting compounds have shown to significantly diminish the cancer stem cell population, inhibit the growth of primary tumors, and reduce metastatic burden (29-33).

In normal tissues, the expression of CA IX is negligible with the exception of the stomach and gallbladder epithelia (34). There is a broad spectrum of aggressive malignancies where CA IX is predominantly overexpressed, namely, neuroblastoma (35), breast tumor (36), head and neck tumors (37), ovarian tumor (38), pancreatic tumor (39), hepatocellular carcinoma (40), etc. In addition, there are several reviews which summarize the significance of CA IX as a promising biomarker for the tumor development (41). Thus, CA IX has emerged as the clinically relevant biomarker and a potential anticancer-drug target.

At the core of $\alpha$-CA active site, the metal ion, Zn (II), is tetrahedrally coordinated to three imidazole rings from His94, 96, and 119 (numbering according to CA II) and a water/hydroxide anion (42). The catalytic site is located at approximately $15 \AA$ depth conical cavity which consists of hydrophobic (Val121, Val143, Leu198, Val207, Trp209) as well as hydrophilic (Tyr7, Asn62, His64, Asn67, Thr199, Thr200) regions and provides the accessibility to the solvent $(22,43,44)$.

PeerJ reviewing PDF | (2017:07:19447:1:1:NEW 23 Oct 2017) 
94 A high conservation of amino acids in the active site and surrounding faces has been found 95 among the 12 catalytically active human CA isoforms $(24,45)$. Thus, the design of CA isoform96 selective inhibitors has been the challenging goal for many researchers. In 1954, acetazolamide 97 was approved in clinic as the first CA-targeting antiglaucoma drug (46). In the next decades, a 98 vast collection of CA inhibitors with various affinities and selectivities has been designed and 99 has been extensively reviewed (47-51).

100 It is a challenging task to design inhibitors that would be not only highly selective to CA IX but 101 also safe for use in humans for the treatment and diagnosis of hypoxic tumors. Many aspects 102 need to be considered to achieve the final goal of developing the promising drugs that could 103 selectively inhibit CA IX in hypoxic tumors. The knowledge about the active site structure of the 104 protein and permeability of the inhibitor across the cell membrane is essential for designing the 105 CA IX specific inhibitors. An inhibitor may be selective for CA IX but it may need to be 106 attached to a conjugate to make it impermeable through the membrane.

107 Similarly, the potential inhibitors need to go through the physical and biochemical screening and 108 various modifications to develop as CA IX isoform specific compounds. The most promising CA 109 IX inhibitors have to be screened for safety and toxicity in vivo using animal models such as 110 zebrafish before subjecting them to preclinical characterization. In addition to chemical 111 compounds that are selective against CA IX, CA IX-selective biological molecules, such as 112 monoclonal antibodies (mAbs), are at various stages of preclinical and clinical trials as potential 113 anticancer agents targeting CA IX in hypoxic tumors. In addition, the anticancer agents based on 114 CA IX selective inhibitors can be conjugated with various probes for the diagnosis of hypoxic 115 tumors.

\section{SURVEY METHODOLOGY}

118 A wide variety of chemical compounds have been described in the literature that target tumor119 associated CA IX. In this review we selectively describe only aromatic sulfonamides that have 120 been demonstrated to bind and inhibit the catalytic domain of recombinant human CA IX by at 121 least two experimental approaches, such as inhibition of enzymatic activity and biophysical 122 assays including the fluorescent thermal shift assay (FTSA), isothermal titration calorimetry 123 (ITC), and surface plasmon resonance (SPR). We emphasize the use of non-mammalian animal 124 models such as zebrafish and Xenopus oocytes for the toxicity, affinity, and selectivity studies of 125 CA IX targeting sulfonamides. Published in 2016-2017, these studies suggest possibilities that 126 could help in the development of antitumor agents prior to preclinical characterization in mice 127 models.

128 For reviewing the information, we identified the articles containing information about different 129 biological and chemical antitumor agents that target CA IX in hypoxic tumors. The literature 130 search was performed using the relevant keywords in PubMed. For example, the antibody 131 section was compiled with all available articles published since 1986 up to 2017, in which the 132 use of antibodies for the detection of CA IX in patients was described. Publications were retained 
133 if they contained relevant information about the promising agents that target CA IX in humans

134 and also during the development of these agents in human cell lines and mice models. Priority

135 was given to the antitumor agents that have been developed either for the treatment or imaging of

136 the tumors using novel strategies.

137 The focus of this review is also to present recent developments in the treatment and diagnosis of 138 solid tumors under hypoxic conditions that express CA IX. We present the recent achievements 139 on the 8 diagnostic tools including chemical and biological antitumor agents targeting CA IX 140 that are at various stages of preclinical and clinical trials for treating the hypoxic tumors. This 141 review combines the information about animal models, enzymatic, biophysical methods used in 142 CA field, as summarized in Figure 1, with the latest references of novel anticancer agents that are 143 currently applied to target CA IX for the diagnosis and treatment.

3. CA INHIBITOR ASSAYS

\section{3.1. CA enzymatic activity inhibition assay}

147 To evaluate the potency of CA-targeting inhibitor, the stopped-flow $\mathrm{CO}_{2}$ hydration assay (SFA) 148 has been widely applied for more than 5 decades since the discovery of the method to measure $149 \mathrm{CA}$ catalyzed $\mathrm{CO}_{2}$ hydration rate by Gibbsons and Edsall and by Khalifah (52-54). This 150 approach is based on the monitoring of the changes in absorbance of $\mathrm{pH}$ sensitive indicator upon $151 \mathrm{CA}$ catalyzed $\mathrm{CO}_{2}$ hydration reaction. The half-maximal inhibitory concentration, $\mathrm{IC}_{50}$, is 152 determined by fitting the compound dose curve according to the Hill model or Morrison equation 153 (55). The inhibition constant, $\mathrm{K}_{\mathrm{i}}$, can be obtained from $\mathrm{IC}_{50}$ value by Cheng-Prusoff equation 154 (56).

155 Supuran and co-authors have developed a large library of CA inhibitors by SFA and divided 156 them into five groups according to CA inhibition mechanisms: (1) the zinc binders (sulfonamides 157 and their isosteres, dithiocarbamates and their isosteres, hydroxamates, etc.) (46, 50, 57-60); (2) 158 compounds that anchor to the zinc-coordinated water molecule/hydroxide ion (phenols, 159 polyamines, sulfocoumarins, etc.) (61-65); (3) inhibitors which occlude the entrance to the CA 160 active site (coumarins and their isosteres) (66-68); (4) compounds which bind out of the active 161 site (carboxylic acid derivates) (69); (5) inhibitors which bind in an unknown way 162 (secondary/tertiary sulfonamides, imatinib, nilotinib, etc.) (70-72). Since these various 163 compounds have been subject of numerous recent reviews, here we concentrate only on aromatic 164 sulfonamides as CA inhibitors. Supuran's group also measured the affinity of monoclonal 165 antibodies to target CA isoforms using SFA (73). In addition to other previously synthesized 166 compounds containing fluorine, our group has identified a series of fluorinated 167 benzenesulfonamides as strong CA IX inhibitors by SFA and have shown a correlation between 168 parameters obtained by enzymatic and biophysical assays (74).

169 Importantly, CA isoforms share not only hydratase but also esterase activity which was 170 discovered in early 1960s (75). Both reactions occur in the same catalytic pocket suggesting 
171 similarities in their mechanisms. The method to determine esterase activity is a high-throughput

172 colorimetric assay with various applications such as screening chemical molecules or antibodies

173 against $\mathrm{CA}$ isozymes $(76,77)$.

174

175

\subsection{Biophysical assays of inhibitor binding to CAs}

176

Advantages and limitations of enzymatic inhibition versus biophysical assays of inhibitor

177 binding have been assessed and are compared in our recent manuscript (78). Biophysical methods not only determine the thermodynamic parameters of ligand binding to CAs but also provide insight into numerous significant factors, which influence the binding: local water structure, hydrogen bonding, hydrophobic interactions, and desolvation. The thermodynamic profiles of drug candidate binding to CA have been widely used. Here we will focus on biophysical techniques, such as fluorescent thermal shift assay (FTSA), isothermal titration calorimetry (ITC), and surface plasmon resonance (SPR), which have been applied in the rational drug design of isoform-selective $\mathrm{CA}$ inhibitors.

\subsubsection{Isothermal titration calorimetry}

187

Since the invention of first analog of an isothermal titration calorimeter in $1966(79,80)$ and its modifications for biological applications in 1980s $(81,82)$, ITC has become the method of choice to study protein target-ligand interactions. During the experiment, in the current commercial titration calorimeters, the inhibitor solution from the syringe is injected at constant temperature into the protein solution preloaded to the calorimeter cell until all binding sites of the protein become occupied by the ligand. Importantly, ITC does not require the inhibitor or protein to be labeled or immobilized and allows the determination of the affinity, the binding enthalpy and the stoichiometry in a single titration experiment (83-86).

Numerous studies of interactions between diverse ligands and target $\mathrm{CA}$ isoforms have been performed by ITC $(22,87,88)$. The binding of anions to CA II was evaluated using ITC, X-ray crystallography, and molecular dynamics simulations by Whitesides group (89). For the deeper understanding of structure-activity relationships, the analysis of buffer ionization effects was performed by ITC upon an inhibitor binding to recombinant human CA isoforms, including CA I (90), CA II (90), CA VB (91), CA VI (92), CA VII (93), CA IX (94), CA XII (95), and CA XIII (96). In addition, ITC standard and displacement titrations were combined with the X-ray crystallographic structures to determine the intrinsic, buffer-independent affinity of para substituted tetrafluorobenzenesulfonamides binding to several human CA isoforms (97).

\subsubsection{Fluorescent thermal shift assay}

206 FTSA, also called differential scanning fluorimetry and, in high-throughput format, 207 ThermoFluor ${ }^{\circledR}$, has been widely applied by numerous researchers and companies, such as 208 Johnson \& Johnson, New Brunswick, United States. It is a rapid screening method in the drug 
209 discovery to measure the binding affinities of chemical compounds to targets (98-101). FTSA

210 monitors the equilibrium of a protein between its folded and unfolded states by detecting the

211 fluorescence of solvatochromic probes, such as 1,8-anilinonaphthalene sulfonate or SYPRO®

212 orange, while the temperature is steadily increased. This method determines the protein melting

213 temperature which can be highly affected by the affinity of ligand and its concentration (102,

214 103). In addition, FTSA is a convenient technique to characterize protein thermal stabilities at

215 various conditions including diverse buffers, excipients, etc $(104,105)$.

216 FTSA has been widely applied in the search of CA inhibitors. The binding of sulfamate and 217 sulfamide derivatives to human CA II was investigated using FTSA by Klinger et al. (106).

218 FTSA was also applied by our group to investigate the interactions between human CA isoforms 219 and various series of inhibitors, including tri- and tetrafluorobenzenesulfonamides (107, 108), 220 benzenesulfonamide derivatives with pyrimidine moieties (109), saccharin sulfonamides (110), 221 benzenesulfonamides with benzimidazole moieties (111), 4-amino-substituted 222 benzenesulfonamides (112). In addition, the profiles of thermal stabilities of recombinant human 223 CA VB (91), CA VI (92), CA IX (94), and CA XII (95) was described using FTSA.

224

225

226

227

228

229

230

231

232

233

234

235

236

237

238

239

240

241

242

243

244

245

\subsubsection{Surface plasmon resonance}

SPR was first demonstrated for the monitoring of biomolecular interactions by Lundstrom et al. in 1983 (113) and the first commercial SPR instrument was launched by Pharmacia Biosensors AB in 1991 (114). During the last decades, SPR biosensors have become the state-of-the-art technology in diagnostics and biomedical research to determine a real-time kinetics and binding affinities of ligand-protein interactions. To screen lead compounds, one of the binding partners, usually the target protein, is immobilized on a metal surface and the ligand flows over that surface by microfluidic system. SPR is a label-free optical method, which measures the changes in refractive index at the metal surface upon the binding reaction.

Studies of SPR application in CA research used recombinant human CA I (115) or mostly CA II (116-118) isoform as a model for the screening of numerous inhibitors. In contrast, Talibov et al. immobilized six human recombinant CA isoforms (full-length CA I, CA II, CA VII, CA XIII, catalytic domains of CA IX and CA XII) and analyzed their interactions with 17 benzenesulfonamide ligands by SPR. Interestingly, results revealed one compound from investigated series to be as a tight binder to recombinant CA IX with the dissociation rates too slow to be determined by SPR (119).

\subsection{Zebrafish model for compound toxicity}

Phenotype-based screening using zebrafish has become a promising high-throughput assay for the drug discovery. This approach revealed that 62\% of drugs approved from 1999 till 2008 were discovered by phenotype-based screens despite that they represented only a small fraction of all 
246

247

248

249

250

251

252

253

254

255

256

257

258

259

260

261

262

263

264

265

266

267

268

269

270

271

272

273

274

275

276

277

278

279

280

281

282

283

284

screens (120). Phenotypic screens possess many significant advantages over target-based screens including the identification of drugs without a validated target or the characterization of the therapeutic profile of the compound, which affects several targets simultaneously. Zebrafish has emerged as a powerful model system for phenotypic screens of drug-candidates in vivo because of many advantages that include high homology between zebrafish and mammalian CAs, low cost, and avoidance of most ethical issues associated with the use of other animals. However, zebrafish lack lung, prostate, and mammary glands, heart septation, limbs, and it is necessary to grow zebrafish at $30{ }^{\circ} \mathrm{C}$, while compounds against mammalian targets are usually optimized for $37^{\circ} \mathrm{C}(121,122)$.

Zebrafish can be particularly useful to carry out toxicological studies of CA inhibitors. Toxic effects of two fluorinated benzenesulfonamides as CA IX inhibitors were investigated on zebrafish development (123). $L C_{50}$ values showed that one compound exhibited 10-fold lower toxicity than ethoxzolamide (EZA), a compound used as a drug in humans. In addition, lightfield microscopy and histological analysis revealed that EZA induced side effects such as pericardial edema, unutilized yolk sac and abnormal body shape of zebrafish. In contrast, developmental abnormalities were not detected in embryos treated with the fluorinated benzenesulfonamides (Table 1). Thus, this study showed that CA IX inhibitors did not have adverse effects on phenotype and morphology of zebrafish larvae. Such toxicological screenings of the compounds using zebrafish could provide information on the safety of lead molecule that could be useful for further development into a drug.

\subsection{Oocyte system for heterologous expression of CAs to determine compound affinity and selectivity}

Since 1960s, the Xenopus laevis has been widely used as a convenient animal model in various biomedical fields including molecular and physiological research. The Xenopus oocytes have many advantages including a large number of offspring, easy manipulations because of their big size (1.1-1.3 mm) and easy maintenance. Furthermore, oocytes feature highly efficient translation of heterologous RNA into protein.

Native Xenopus oocytes do not possess any CA activity and thus have become a convenient in vivo model system to investigate CA inhibitors. The enzymatic activity of CA can be evaluated with microelectrodes while monitoring the intracellular and extracellular acidification. Results can be confirmed by mass spectrometric gas analysis of lysed or intact oocytes (124). The transfection of Xenopus oocytes with cRNA of CA isozymes has been published by Deitmer's group $(125,126)$. They showed the complete inhibition of CA IX enzymatic activity with $30 \mu \mathrm{M}$ EZA according to the rates of cytosolic $\mathrm{pH}$ changes and amplitudes of $\mathrm{pH}$ changes at the outer membrane side (125). The same effect was found in CA IX expressing oocytes treated with 1 $\mu \mathrm{M}$ fluorinated benzenesulfonamide targeting CA IX (127). The $I C_{50}$ was found to be in the range of 15-25 $\mathrm{nM}$ for both intracellularly and extracellularly expressed CA IX. Moreover, the compound exhibited strong selectivity over CA II, CA IV or CA XII in oocytes expressing a 
285 particular CA isoform (Table 1). This novel in vivo approach allows the identification of the 286 affinity and selectivity of CA IX inhibitors in the living eukaryotic cell with fully matured target 287 CA isozyme.

288

\section{CA IX-TARGETED STRATEGIES}

291

Targeting CA IX enzyme is a promising approach for the development of new therapeutics against hypoxic tumors. There are several agents that can selectively target CA IX by using

292 different strategies. Here, we present therapeutic agents that have been used against CA IX for

293 diagnosis and treatment of hypoxic tumors in humans (Table 2).

294

\subsection{Monoclonal antibodies for CA IX-targeted therapy}

297

M75 and chimeric G250 (cG250) are two widely-applied monoclonal antibodies (mAbs)

298

299

300

301

302

303

304

305

306

307

308

309

310

311

312

313

314

315

316

317

318

319

320

321 recognizing human CA IX. These mAbs have been used for clinical detection or therapy (128, 129). The M75 targets the PG-domain of CA IX and is used for the detection of CA IX in human tissues (130-132). cG250 has been successfully developed for anticancer immunotherapy (133) due to its ability to elicit antibody-dependent cellular cytotoxicity (134). The clinical trials showed that cG250 is safe, and has effect on the disease burden, when applied alone or together with interferon- $\alpha(135,136)$. This mAb is marketed by WILEX AG using RENCAREX ${ }^{\circledR}$ as a trade name and has been used for renal cell carcinoma patients (RCC) who are at high risk of relapse (137). In the recent past, this mAb under the name of girentuximab, has been assessed as an adjuvant in Phase III ARISER trial in RCC patients and showed that the patients expressing CA IX benefited more than ones without or minimal expression of CA IX (138). In a phase II study, the mAb labeled with lutetium $\left({ }^{177}\right.$ Lu-girentuximab) demonstrated the significantly positive impact on the progressive metastatic ccRCC patients (139). In addition, REDECTANE® (124I-girentuximab) has been in clinical development targeting ccRCC (140). Furthermore, A3 and CC7 have been developed as CA IX-selective mAbs by the phage display method. They showed promising results in animal models of colorectal cancer and may be useful for the drug delivery (128). These studies clearly showed that mAbs and their modified versions are potential candidates for the development as anticancer agents targeting tumors that express CA IX.

Several monoclonal antibodies have been developed that influence the catalytic activity of CA IX (141). Pastorekova's group has demonstrated that the mAb VII/20 binds to the catalytic domain of CA IX, causing the receptor-mediated internalization of the antibody-protein complex. Authors have shown that this process is important for the immunotherapy because significant anticancer effects of VII/20 were found in mouse xenograft model of colorectal carcinoma (142). Thus, the application of CA IX-targeting antibodies might be significantly beneficial immunotherapeutic strategy. 
322 Furthermore, mAbs have been considered as the ligands of choice for the design of antibody323 drug conjugates (ADCs). In current clinical development, there are 65 ADCs mostly targeting 324 various proteins at cell surface $(143,144)$. Since antibodies might cause problems related with 325 the penetration or immunogenicity, there is a demand for smaller agents, such as peptides or 326 chemical derivatives, for the drug delivery. Recently, Neri with co-authors has described CA IX327 targeting small-molecule drug conjugates. Monovalent and divalent conjugates of acetazolamide 328 with the cytotoxic maytansinoid DM1 exhibited promising anticancer activity in SKRC52 renal 329 cell carcinoma in vivo $(145,146)$.

\section{4.2 Chemical compounds targeting CA IX for therapy}

332 A wide range of CA IX selective inhibitors has been designed with the help of X-ray 333 crystallography and computational analysis. Among them, a group of sulfonamides show 334 potential for developing as anticancer agents. A sulfonamide compound, indisulam, has shown a significant antitumor activity in preclinical cancer models (147). Phase II clinical trials were conducted to determine the efficacy, safety and tolerability of indisulam in combination with irinotecan in patients with metastatic colorectal cancer who were previously treated with 5fluorouracil/leucovorin and oxaliplatin (148) but no further information is available about the outcome of the trial. Similarly, bis-sulfonamides have shown promising results in vitro in tumor sections and target tumors in vivo (149). Preclinical studies using ureidosulfonamide inhibitor of CA IX, named as U-104 or SLC-0111 (SignalChem Lifesciences Corp), showed positive effects with the negligible toxicity for the treatment of various tumors $(150,151)$. Recently, U-104 has been demonstrated to be effective in vitro and in vivo models of the pancreatic ductal adenocarcinoma (Pt45.P1/asTF+). U-104 significantly decreased the growth of pancreatic cells in hypoxia but not in normoxia and reduced the tumor growth in mice emphasizing the potential of the compound as a therapeutic agent against CA IX (152).

Small molecule-drug conjugates (SMDCs) have been used for the selective delivery of therapeutic agents to tumor sites. The series of stable and therapeutically active SMDCs were generated by attaching acetazolamide to monomethyl auristatin E using dipeptide linkers. They showed a promising antitumor activity in mice bearing SKRC-52 renal tumors. Since CA IX is a transmembrane protein, the findings of this study is significantly important for the targeted drug delivery in kidney cancer patients (153). Similarly, PEGylated bis-sulfonamide CA inhibitors were synthesized from aminosulfonamide pharmacophores conjugated with either ethyleneglycol oligomeric or polymeric diamines. These compounds efficiently controlled the growth of several CA IX-expressing cancer cell lines including colon HT-29, breast MDA-MB-23, and ovarian SKOV-3 (154).

To demonstrate the antitumor effect of CA IX inhibition in vivo, the vast library of conjugates against CA IX has been designed. Dual targeting bioreductive nitroimidazole-based sulfamide drug, named as DH348, was used to evaluate the impact on the extracellular acidification and radiosensitivity in HT-29 colorectal cancer cells and mouse xenograft models. By using nontoxic 
361 doses of DH348, the hypoxia-induced extracellular acidification was significantly reduced and 362 the tumor growth was decreased. DH348 also sensitized the tumor to irradiation and the effect 363 was CA IX-dependent (155). In addition, the combination of SLC-0111 and APX3330 has been 364 reported in patient-derived 3D pancreatic cancer models. Results of dual treatment showed a 365

366

367

368

369

370

\section{1}

372

373

374

375

376

377

378

379

380

381

382

383

384

385

386

387

388

389

390

391

392

393

394

395

396

397 greater decrease in the intracellular $\mathrm{pH}$ and 3D tumor spheroid growth than treatment with either inhibitor alone (156). Recently, phase I clinical trial of SLC-0111 has been finished and the compound was scheduled to enter Phase II trials (157). Since results of phase I trials have not been published, the characterization of pharmacodynamics and pharmacokinetics of SLC-0111 is not available yet.

\subsection{Targeting CA IX using nanoparticles}

Gold nanoparticles coated with chemical inhibitors are a relatively new to the field of the development of agents targeting CA IX. The gold nanoparticles modified with CA IX inhibitors cannot pass through the membrane. Thus, they show a great potency to be effective in targeting and inhibiting the extracellular active site of CA IX.

The nanoparticles, which were modified with thiols and benzenesulfonamide groups, selectively inhibited CA IX $\left(\mathrm{K}_{\mathrm{i}} 32 \mathrm{nM}\right)$ but their affinities toward CA I and CA II were more than 10-folds lower $\left(\mathrm{K}_{\mathrm{i}} 451 \mathrm{nM}\right)$. In addition, these nanoparticles possessed a greater affinity toward CA IX than acetazolamide and may be suitable candidates for imaging and treatment of hypoxic tumors (158). Recently, gold nanoparticles were used to target CA IX for photoacoustic imaging and optical hyperthermia (159). In addition, derivatives of benzenesulfonamides combined with nanorods showed a significant impact on the reduction of the extracellular acidification in hypoxic human mammary and colorectal carcinomas (160). These studies suggest that the use of nanoparticles can be used to efficiently target extracellular part of CA IX in hypoxic tumors.

To improve the potency and selectivity of novel inhibitors, recently multivalent nanoconstructs have been developed $(161,162)$. These nanoconstructs showed excellent inhibitory effects with $\mathrm{K}_{\mathrm{i}}$ values of 6.2-0.67 nM against tested CA isozymes. They contain multiple copies of a ligand, which are displayed closely on the same derivative. Thus, a weak $\mathrm{mM}$ binder can be changed to $\mathrm{nM}$ binder and the biomolecular recognition can be enhanced (163). Even though the use of multivalent nanoconstructs in the field of CA IX inhibition is quite recent, there is a great potential to develop CA IX inhibitors with high affinity and selectivity properties using this multivalent strategy.

\section{IMAGING METHODS}

Detection of hypoxic regions of solid tumors is an important step for cancer treatment (164). The application of selective ligands against CA IX in diagnostic imaging has been widely investigated. They could help to decide which patients can get benefit from the adjunctive 
398 therapy (165). Both antibodies and small molecular weight compounds have been used for non-

399 invasive imaging of CA IX in a number of aggressive and late stage types of tumors and 400 metastases (137).

401

402

403

404

405

406

407

408

409

410

411

412

413

414

415

416

417

418

419

420

421

422

423

424

425

426

427

428

429

430

431

432

433

434

\subsection{Imaging of tumors using CA IX-specific mAbs}

CA IX is a useful biomarker for clear cell renal cell carcinoma (ccRCC) because CA IX is absent in normal kidney tissues. The CA IX-specific cG250, radiolabeled with iodine-124 or zirconium89 , has been used for the diagnosis of ccRCC (166). High parameters of sensitivity and specificity were determined by positron emission tomography/computed tomography (PET/CT) when cG250 labeled with iodine-124 was applied for the imaging of ccRCC (167). This study suggests a great potential to monitor ccRCC in patients and allows the differentiation of ccRCC versus non-ccRCC.

An iodine-125 radiolabelled M75, CA IX-selective mAb, has been developed for pre-clinical imaging of CA IX in hypoxic tumors in mouse xenograft models $(130,131)$. In addition, human A3 and CC7 mini-antibodies have been designed. Their small size enables them to distribute faster compared to full sized antibodies. These antibodies do not inhibit the catalytic activity of CA IX and are selective for the extracellular domain of human CA IX (168). By using mAbs coated with near-infrared fluorescent (NIRF) molecules, molecular imaging probes have been developed and applied for the non-invasive detection of breast cancer axillary lymph node (ALN) metastases. The high selectivity of these probes have been confirmed in vitro and in vivo using models of preclinical breast cancer metastasis (169).

\subsection{Affibody molecules for imaging of CA IX expression}

The affibodies are specially engineered small proteins that can bind to target proteins with a high affinity similarly to mAbs. These molecules can be used as novel anticancer drugs and/or for radionuclide imaging of tumors. In a recent study, several in vitro and in vivo properties of affibodies labeled with ${ }^{99 \mathrm{~m}} \mathrm{Tc}$ and ${ }^{125} \mathrm{I}$ were characterized. Tested affibodies were highly specific to CA IX in SK-RC-52 cells and selectively accumulated in SK-RC-52 xenografts (170). The study suggests the usefulness of CA IX-binding affibodies for cancer detection and therapy.

\subsection{Imaging of CA IX expression with small molecular chemical probes}

Chemical probes can be applied for labeling and detection of biomolecules in order to study molecular processes occurring within living cells. The sulfonamide-based CA inhibitors efficiently bind to CA IX in hypoxic tumors as the active site of the enzymes is only available upon hypoxic conditions (171). Unlike CA IX-specific mAbs, sulfonamides can recognize cells that are in hypoxic conditions. Thus, CA IX inhibitors and mAbs can give the different information about imaging and prognosis (172). To prevent the sulfonamide-based inhibitors 
435 from passing through the membrane, inhibitors can be conjugated with fluorescent dye (FITC), 436 albumin or hydrophilic sugar moieties that would prevent their entry into the cell (173). Among 437 them, sulfonamides attached to FITC were shown to be membrane-impermeable with a high 438 affinity to CA IX. This imaging agent was able to bind to CA IX, expressed in cells under 439 hypoxic but not normoxic conditions (171). Similarly, acetazolamide-based derivatives bearing 440 many types of NIRF dyes were designed as promising probes for the imaging of hypoxiainduced CA IX in tumor cells. Compounds were characterized to be up to 50-fold selective to

442 CA IX compared to CA II. In preclinical studies using mice with HT-29 tumors, the significant impact of CA IX inhibitors with NIRF group on the non-invasive quantification of CA IX was determined (174). Moreover, fluorescent sulfonamides containing a charged fluorophore have been used in vivo and have shown a great efficiency in detecting CA IX in HT-29 and SK-RC-52 tumor xenografts $(175,176)$.

\subsection{Imaging hypoxic tumor areas with nonpeptidic ligand conjugates.}

450

451

452

453

454

455

456

457

458

459

460

461

462

463

464

465

466

467

468

469

470

471

Recently, nonpeptidic ligand conjugates have been evaluated for single-photon emission computed tomography (SPECT) imaging of hypoxic cancers that express CA IX (177). For a better clinical care, a broader knowledge about the level of hypoxia is needed. CA IX-targeting ligand was synthesized with the aim to deliver the attached ${ }^{99 \mathrm{~m}} \mathrm{Tc}$-chelating agent to hypoxic regions. The studies of binding characterization in vitro and imaging of the biodistribution in vivo were carried out. Results showed that several such conjugates can selectively bind to CA IX in tumors. This study revealed the significantly important applications of nonpeptidic ligand conjugates to evaluate the level of hypoxia in tumors (177).

In summary, the mAbs G250 and M75 have the advantages of binding to CA IX selectively on the surface of cancer cells, and thus they are able to detect cancer cells that overexpress CA IX. This is because the mAbs are raised against specific epitopes of CA IX, and they are unable to pass through the cell membranes due to the high molecular weight. However, the mAbs (G250 and M75) bind to the PG domain, and therefore they cannot affect its catalytic activity. In contrast, chemical inhibitors recognize the active site and can inhibit the enzymatic activity of CA IX, but they might possess several disadvantages including the low selectivity because of similarity of the $\alpha$-CAs active sites, and the permeation through the plasma membrane. Thus, they might have off-target effects because of affinity to both intracellular and extracellular CAs. If the chemical inhibitors are conjugated with bulky molecules to avoid the internalization, they may still bind to other membrane CAs, such as CA XII. Thus, the properties of mAbs and chemical inhibitors need to be taken into consideration for using them as anticancer agents or as probes for the imaging of solid tumors.

\section{CONCLUSION}


472 The critical role of CA IX in the tumor progression and aggressiveness has been shown and CA 473 IX has been proposed as a promising therapeutic drug target and a clinically useful biomarker of 474 the broad range of hypoxic tumors. Our review described efforts in the development of selective 475 agents against CA IX. It is a challenging task to develop a compound of high affinity and 476 selectivity towards only one CA isoform due to the high homology between twelve catalytically

477 active CA isoforms in human body. Deeper insight in the structural analysis and interactions of 478 proteins involved in $\mathrm{pH}$ regulatory mechanisms of tumor cell could provide the relevant new 479 strategies for rational drug design of CA IX-selective compounds for the therapy and diagnostic 480 imaging.

481

482 LIST OF ABBREVIATIONS

483 ADCs - Antibody-drug conjugates

484 ALN - Axillary lymph node

485 EZA- Ethoxzolamide

$486 \mathrm{IC}_{50}$ - The concentration causing $50 \%$ inhibition of target activity

487 CA - Carbonic anhydrase

488 ccRCC - Clear cell renal cell carcinoma

489 FITC - fluorescent dye

490 FTSA - Fluorescent thermal shift assay

491 HIF - Hypoxia-inducible factor

492 ITC - Isothermal titration calorimetry

493 mAbs - Monoclonal antibodies

494 NIRF - Near-infrared fluorescent

495 PET/CT - Positron emission tomography/computed tomography

496 SFA - Stopped-flow $\mathrm{CO}_{2}$ hydration assay

497 SLC - SignalChem Lifesciences Corp

498 SMDCs - Small molecule-drug conjugates

499 SPECT-Single-photon emission computed tomography

500 SPR - Surface plasmon resonance

501 U-104 - Ureidosulfonamide inhibitor of CA IX 


\section{REFERENCES}

503

Semenza, G. L. (2014) Oxygen Sensing, Hypoxia-Inducible Factors, and Disease Pathophysiology, Annual Review of Pathology 9, 4771.

Hanahan, D., and Weinberg, R. A. (2011) Hallmarks of Cancer: The next Generation, Cell 144, 646-674.

Welti, J., Loges, S., Dimmeler, S., and Carmeliet, P. (2013) Recent Molecular Discoveries in Angiogenesis and Antiangiogenic Therapies in Cancer, The Journal of Clinical Investigation 123, 3190-3200.

4. Warburg, O. (1956) On Respiratory Impairment in Cancer Cells, Science (New York, N.Y.) 124, 269-270.

5. Vander Heiden, M. G., Cantley, L. C., and Thompson, C. B. (2009) Understanding the Warburg Effect: The Metabolic Requirements of Cell Proliferation, Science (New York, N.Y.) 324, 1029-1033.

6. Wojtkowiak, J. W., Verduzco, D., Schramm, K. J., and Gillies, R. J. (2011) Drug Resistance and Cellular Adaptation to Tumor Acidic pH Microenvironment, Molecular Pharmaceutics 8, 2032-2038.

7. Good, J. S., and Harrington, K. J. (2013) The Hallmarks of Cancer and the Radiation Oncologist: Updating the 5Rs of Radiobiology, Clinical Oncology (Royal College of Radiologists (Great Britain)) 25, 569-577.

8. Denko, N. C. (2008) Hypoxia, HIF1 and Glucose Metabolism in the Solid Tumour, Nature Reviews. Cancer 8, 705-713.

9. Ryu, M. H., Park, H. M., Chung, J., Lee, C. H., and Park, H. R. (2010) Hypoxia-Inducible Factor-1alpha Mediates Oral Squamous Cell Carcinoma Invasion via Upregulation of Alpha5 Integrin and Fibronectin, Biochemical and Biophysical Research Communications $393,11-15$

10. O'Toole, E. A., Koningsveld, R. van, Chen, M., and Woodley, D. T. (2008) Hypoxia Induces Epidermal Keratinocyte Matrix Metalloproteinase-9 Secretion via the Protein Kinase C Pathway, Journal of Cellular Physiology 214, 47-55.

11. Li, Y., Qiu, X., Zhang, S., Zhang, Q., and Wang, E. (2009) Hypoxia Induced CCR7 Expression via HIF-1alpha and HIF-2alpha Correlates with Migration and Invasion in Lung Cancer Cells, Cancer Biology \& Therapy 8, 322-330.

12. Kotch, L. E., Iyer, N. V., Laughner, E., and Semenza, G. L. (1999) Defective Vascularization of HIF-1alpha-Null Embryos Is Not Associated with VEGF Deficiency but with Mesenchymal Cell Death, Developmental Biology 209, 254-267.

13. Takubo, K., Goda, N., Yamada, W., Iriuchishima, H., Ikeda, E., Kubota, Y., Shima, H., Johnson, R. S., Hirao, A., Suematsu, M., and Suda, T. (2010) Regulation of the HIF-1alpha Level Is Essential for Hematopoietic Stem Cells, Cell Stem Cell 7, 391-402.

14. Obach, M., Navarro-Sabaté, A., Caro, J., Kong, X., Duran, J., Gómez, M., Perales, J. C., Ventura, F., Rosa, J. L., and Bartrons, R. (2004) 6-Phosphofructo-2-Kinase (Pfkfb3) Gene Promoter Contains Hypoxia-Inducible Factor-1 Binding Sites Necessary for Transactivation in Response to Hypoxia, The Journal of Biological Chemistry 279, 53562-53570.

15. Ullah, M. S., Davies, A. J., and Halestrap, A. P. (2006) The Plasma Membrane Lactate Transporter MCT4, but Not MCT1, Is UpRegulated by Hypoxia through a HIF-1 $\alpha$-Dependent Mechanism, Journal of Biological Chemistry 281, 9030-9037.

16. Parks, S. K., Chiche, J., and Pouysségur, J. (2013) Disrupting Proton Dynamics and Energy Metabolism for Cancer Therapy, Nature Reviews. Cancer 13, 611-623.

17. Wilson, W. R., and Hay, M. P. (2011) Targeting Hypoxia in Cancer Therapy, Nature Reviews. Cancer 11, 393-410.

18. Hashim, A. I., Zhang, X., Wojtkowiakk, J. W., and Gillies, R. J. (2011) Imaging pH and Metastasis, NMR in biomedicine 24, $582-591$.

19. Mazzio, E. A., Smith, B., and Soliman, K. F. A. (2010) Evaluation of Endogenous Acidic Metabolic Products Associated with Carbohydrate Metabolism in Tumor Cells, Cell biology and toxicology 26, 177-188.

20. Prete, S. D., Vullo, D., Luca, V. D., Supuran, C. T., and Capasso, C. (2014) Biochemical Characterization of the ẹta-Carbonic Anhydrase from the Marine Diatom Thalassiosira Weissflogii, TweCA, Journal of Enzyme Inhibition and Medicinal Chemistry 29, 906-911.

21. Supuran, C. T., and Capasso, C. (2015) The $\eta$-Class Carbonic Anhydrases as Drug Targets for Antimalarial Agents, Expert Opinion on Therapeutic Targets 19, 551-563.

22. Krishnamurthy, V. M., Kaufman, G. K., Urbach, A. R., Gitlin, I., Gudiksen, K. L., Weibel, D. B., and Whitesides, G. M. (2008) Carbonic Anhydrase as a Model for Biophysical and Physical-Organic Studies of Proteins and Protein-Ligand Binding, Chemical Reviews 108, 946-1051.

23. Kikutani, S., Nakajima, K., Nagasato, C., Tsuji, Y., Miyatake, A., and Matsuda, Y. (2016) Thylakoid Luminal texttheta-Carbonic Anhydrase Critical for Growth and Photosynthesis in the Marine Diatom Phaeodactylum Tricornutum, Proceedings of the National Academy of Sciences of the United States of America 113, 9828-9833.

24. Aggarwal, M., Boone, C. D., Kondeti, B., and McKenna, R. (2013) Structural Annotation of Human Carbonic Anhydrases, Journal of Enzyme Inhibition and Medicinal Chemistry 28, 267-277.

25. Capasso, C., and Supuran, C. T. (2015) An Overview of the Alpha-, Beta- and Gamma-Carbonic Anhydrases from Bacteria: Can Bacterial Carbonic Anhydrases Shed New Light on Evolution of Bacteria?, Journal of Enzyme Inhibition and Medicinal Chemistry 30 , 325-332.

26. Frost, S. C. (2014) Physiological Functions of the Alpha Class of Carbonic Anhydrases, Sub-Cellular Biochemistry 75, 9-30.

27. Alterio, V., Hilvo, M., Fiore, A. D., Supuran, C. T., Pan, P., Parkkila, S., Scaloni, A., Pastorek, J., Pastorekova, S., Pedone, C., Scozzafava, A., Monti, S. M., and Simone, G. D. (2009) Crystal Structure of the Catalytic Domain of the Tumor-Associated Human Carbonic Anhydrase IX, Proceedings of the National Academy of Sciences 106, 16233-16238.

28. Svastova, E., Witarski, W., Csaderova, L., Kosik, I., Skvarkova, L., Hulikova, A., Zatovicova, M., Barathova, M., Kopacek, J., Pastorek, J., and Pastorekova, S. (2012) Carbonic Anhydrase IX Interacts with Bicarbonate Transporters in Lamellipodia and Increases Cell Migration via Its Catalytic Domain, The Journal of Biological Chemistry 287, 3392-3402.

29. Swietach, P., Hulikova, A., Vaughan-Jones, R. D., and Harris, A. L. (2010) New Insights into the Physiological Role of Carbonic Anhydrase IX in Tumour pH Regulation, Oncogene 29, 6509-6521.

30. Pastorek, J., and Pastorekova, S. (2015) Hypoxia-Induced Carbonic Anhydrase IX as a Target for Cancer Therapy: From Biology to Clinical Use, Seminars in Cancer Biology 31, 52-64.

31. Sedlakova, O., Svastova, E., Takacova, M., Kopacek, J., Pastorek, J., and Pastorekova, S. (2014) Carbonic Anhydrase IX, a HypoxiaInduced Catalytic Component of the pH Regulating Machinery in Tumors, Frontiers in Physiology 4.

32. Lock, F. E., McDonald, P. C., Lou, Y., Serrano, I., Chafe, S. C., Ostlund, C., Aparicio, S., Winum, J.-Y., Supuran, C. T., and Dedhar, S. (2013) Targeting Carbonic Anhydrase IX Depletes Breast Cancer Stem Cells within the Hypoxic Niche, Oncogene 32, 5210-5219. 
570 33. McDonald, P. C., Winum, J.-Y., Supuran, C. T., and Dedhar, S. (2010) Recent Developments in Targeting Carbonic Anhydrase IX for Cancer Therapeutics, Oncotarget 1, 84-97.

34. Pastorekova, S., Parkkila, S., Parkkila, A., Opavsky, R., Zelnik, V., Saarnio, J., and Pastorek, J. (1997) Carbonic Anhydrase IX, MN/CA IX: Analysis of Stomach Complementary DNA Sequence and Expression in Human and Rat Alimentary Tracts, Gastroenterology 112, 398-408.

35. Ameis, H. M., Drenckhan, A., Freytag, M., Izbicki, J. R., Supuran, C. T., Reinshagen, K., Holland-Cunz, S., and Gros, S. J. (2016) Carbonic Anhydrase IX Correlates with Survival and Is a Potential Therapeutic Target for Neuroblastoma, Journal of Enzyme Inhibition and Medicinal Chemistry 31, 404-409.

36. Betof, A. S., Rabbani, Z. N., Hardee, M. E., Kim, S. J., Broadwater, G., Bentley, R. C., Snyder, S. A., Vujaskovic, Z., Oosterwijk, E., Harris, L. N., Horton, J. K., Dewhirst, M. W., and Blackwell, K. L. (2012) Carbonic Anhydrase IX Is a Predictive Marker of Doxorubicin Resistance in Early-Stage Breast Cancer Independent of HER2 and TOP2A Amplification, British Journal of Cancer 106, 916-922.

37. Yang, J.-S., Chen, M.-K., Yang, S.-F., Chang, Y.-C., Su, S.-C., Chiou, H.-L., Chien, M.-H., and Lin, C.-W. (2014) Increased Expression of Carbonic Anhydrase IX in Oral Submucous Fibrosis and Oral Squamous Cell Carcinoma, Clinical Chemistry and Laboratory Medicine 52, 1367-1377.

38. Choschzick, M., Oosterwijk, E., Müller, V., Woelber, L., Simon, R., Moch, H., and Tennstedt, P. (2011) Overexpression of Carbonic Anhydrase IX (CAIX) Is an Independent Unfavorable Prognostic Marker in Endometrioid Ovarian Cancer, Virchows Archiv 459, 193 200.

39. Couvelard, A., O’Toole, D., Turley, H., Leek, R., Sauvanet, A., Degott, C., Ruszniewski, P., Belghiti, J., Harris, A. L., Gatter, K., and Pezzella, F. (2005) Microvascular Density and Hypoxia-Inducible Factor Pathway in Pancreatic Endocrine Tumours: Negative Correlation of Microvascular Density and VEGF Expression with Tumour Progression, British Journal of Cancer 92, 94-101.

40. Huang, W.-J., Jeng, Y.-M., Lai, H.-S., Fong, I.-U., Sheu, F.-Y. B., Lai, P.-L., and Yuan, R.-H. (2015) Expression of Hypoxic Marker Carbonic Anhydrase IX Predicts Poor Prognosis in Resectable Hepatocellular Carcinoma, PLoS ONE 10.

41. Kuijk, S. J. A. van, Yaromina, A., Houben, R., Niemans, R., Lambin, P., and Dubois, L. J. (2016) Prognostic Significance of Carbonic Anhydrase IX Expression in Cancer Patients: A Meta-Analysis, Frontiers in Oncology 6.

42. Fisher, S. Z., Maupin, C. M., Budayova-Spano, M., Govindasamy, L., Tu, C., Agbandje-McKenna, M., Silverman, D. N., Voth, G. A., and McKenna, R. (2007) Atomic Crystal and Molecular Dynamics Simulation Structures of Human Carbonic Anhydrase II:, Insights into the Proton Transfer Mechanism, Biochemistry 46, 2930-2937.

43. Eriksson, A. E., Jones, T. A., and Liljas, A. (1988) Refined Structure of Human Carbonic Anhydrase II at 2.0 A Resolution, Proteins 4, 274-282.

44. Pocker, Y., and Sarkanen, S. (1978) Carbonic Anhydrase: Structure Catalytic Versatility, and Inhibition, Advances in Enzymology and Related Areas of Molecular Biology 47, 149-274.

45. Pinard, M. A., Mahon, B., McKenna, R., Pinard, M. A., Mahon, B., and McKenna, R. (2015) Probing the Surface of Human Carbonic Anhydrase for Clues towards the Design of Isoform Specific Inhibitors, Probing the Surface of Human Carbonic Anhydrase for Clues towards the Design of Isoform Specific Inhibitors, BioMed Research International, BioMed Research International 2015, 2015, e453543.

46. Supuran, C. T. (2012) Structure-Based Drug Discovery of Carbonic Anhydrase Inhibitors, Journal of Enzyme Inhibition and Medicinal Chemistry 27, 759-772.

47. Lomelino, C., and McKenna, R. (2016) Carbonic Anhydrase Inhibitors: A Review on the Progress of Patent Literature (2011-2016), Expert Opinion on Therapeutic Patents 26, 947-956.

48. Supuran, C. T. (2016) How Many Carbonic Anhydrase Inhibition Mechanisms Exist?, Journal of Enzyme Inhibition and Medicinal Chemistry 31, 345-360.

49. Supuran, C. T. (2017) Advances in Structure-Based Drug Discovery of Carbonic Anhydrase Inhibitors, Expert Opinion on Drug Discovery 12, 61-88.

50. Alterio, V., Di Fiore, A., D’Ambrosio, K., Supuran, C. T., and De Simone, G. (2012) Multiple Binding Modes of Inhibitors to Carbonic Anhydrases: How to Design Specific Drugs Targeting 15 Different Isoforms?, Chemical Reviews 112, 4421-4468.

51. Monti, S. M., Supuran, C. T., and De Simone, G. (2013) Anticancer Carbonic Anhydrase Inhibitors: A Patent Review (2008 - 2013$)$, Expert Opinion on Therapeutic Patents 23, 737-749.

52. Gibbons, B. H., and Edsall, J. T. (1963) RATE OF HYDRATION OF CARBON DIOXIDE AND DEHYDRATION OF CARBONIC ACID AT 25 DEGREES, The Journal of Biological Chemistry 238, 3502-3507.

53. Gibbons, B. H., and Edsall, J. T. (1964) KINETIC STUDIES OF HUMAN CARBONIC ANHYDRASES B AND C, The Journal of Biological Chemistry 239, 2539-2544.

54. Khalifah, R. G. (1971) The Carbon Dioxide Hydration Activity of Carbonic Anhydrase. I. Stop-Flow Kinetic Studies on the Native Human Enzymes B and C, Journal of Biological Chemistry 246, 2561-73.

55. Morrison, J. F. (1969) Kinetics of the Reversible Inhibition of Enzyme-Catalysed Reactions by Tight-Binding Inhibitors, Biochimica Et Biophysica Acta 185, 269-286.

56. Cheng, Y., and Prusoff, W. H. (1973) Relationship between the Inhibition Constant (K1) and the Concentration of Inhibitor Which Causes 50 per Cent Inhibition (I50) of an Enzymatic Reaction, Biochemical Pharmacology 22, 3099-3108.

57. Carta, F., Akdemir, A., Scozzafava, A., Masini, E., and Supuran, C. T. (2013) Xanthates and Trithiocarbonates Strongly Inhibit Carbonic Anhydrases and Show Antiglaucoma Effects in Vivo, Journal of Medicinal Chemistry 56, 4691-4700.

58. Innocenti, A., Scozzafava, A., and Supuran, C. T. (2010) Carbonic Anhydrase Inhibitors. Inhibition of Transmembrane Isoforms IX, XII, and XIV with Less Investigated Anions Including Trithiocarbonate and Dithiocarbamate, Bioorganic \& Medicinal Chemistry Letters 20, 1548-1550.

59. Carta, F., Aggarwal, M., Maresca, A., Scozzafava, A., McKenna, R., Masini, E., and Supuran, C. T. (2012) Dithiocarbamates Strongly Inhibit Carbonic Anhydrases and Show Antiglaucoma Action in Vivo, Journal of Medicinal Chemistry 55, 1721-1730.

60. Supuran, C. T. (2013) Carbonic Anhydrase Inhibitors: An Editorial, Expert Opinion on Therapeutic Patents 23, 677-679.

61. Nocentini, A., Ceruso, M., Carta, F., and Supuran, C. T. (2016) 7-Aryl-Triazolyl-Substituted Sulfocoumarins Are Potent, Selective Inhibitors of the Tumor-Associated Carbonic Anhydrase IX and XII, Journal of Enzyme Inhibition and Medicinal Chemistry 31, 12261233. 
639 62. Davis, R. A., Vullo, D., Supuran, C. T., and Poulsen, S.-A. (2014) Natural Product Polyamines That Inhibit Human Carbonic

640

Anhydrases, BioMed Research International 2014, e374079.

63. Carta, F., Temperini, C., Innocenti, A., Scozzafava, A., Kaila, K., and Supuran, C. T. (2010) Polyamines Inhibit Carbonic Anhydrases by Anchoring to the Zinc-Coordinated Water Molecule, Journal of Medicinal Chemistry 53, 5511-5522.

64. Innocenti, A., Vullo, D., Scozzafava, A., and Supuran, C. T. (2008) Carbonic Anhydrase Inhibitors: Interactions of Phenols with the 12 Catalytically Active Mammalian Isoforms (CA I-XIV), Bioorganic \& Medicinal Chemistry Letters 18, 1583-1587.

65. Santos, M. A., Marques, S., Vullo, D., Innocenti, A., Scozzafava, A., and Supuran, C. T. (2007) Carbonic Anhydrase Inhibitors: Inhibition of Cytosolic/Tumor-Associated Isoforms I, II, and IX with Iminodiacetic Carboxylates/Hydroxamates Also Incorporating Benzenesulfonamide Moieties, Bioorganic \& Medicinal Chemistry Letters 17, 1538-1543.

66. Nocentini, A., Carta, F., Ceruso, M., Bartolucci, G., and Supuran, C. T. (2015) Click-Tailed Coumarins with Potent and Selective Inhibitory Action against the Tumor-Associated Carbonic Anhydrases IX and XII, Bioorganic \& Medicinal Chemistry 23, $6955-6966$.

67. Bozdag, M., Alafeefy, A. M., Altamimi, A. M., Vullo, D., Carta, F., and Supuran, C. T. (2017) Coumarins and Other Fused Bicyclic Heterocycles with Selective Tumor-Associated Carbonic Anhydrase Isoforms Inhibitory Activity, Bioorganic \& Medicinal Chemistry $25,677-683$.

68. Tars, K., Vullo, D., Kazaks, A., Leitans, J., Lends, A., Grandane, A., Zalubovskis, R., Scozzafava, A., and Supuran, C. T. (2013) Sulfocoumarins (1,2-Benzoxathiine-2,2-Dioxides): A Class of Potent and Isoform-Selective Inhibitors of Tumor-Associated Carbonic Anhydrases, Journal of Medicinal Chemistry 56, 293-300.

69. D’Ambrosio, K., Carradori, S., Monti, S. M., Buonanno, M., Secci, D., Vullo, D., Supuran, C. T., and De Simone, G. (2015) Out of the Active Site Binding Pocket for Carbonic Anhydrase Inhibitors, Chemical Communications (Cambridge, England) 51, 302-305.

70. Parkkila, S., Innocenti, A., Kallio, H., Hilvo, M., Scozzafava, A., and Supuran, C. T. (2009) The Protein Tyrosine Kinase Inhibitors Imatinib and Nilotinib Strongly Inhibit Several Mammalian Alpha-Carbonic Anhydrase Isoforms, Bioorganic \& Medicinal Chemistry Letters 19, 4102-4106.

71. Supuran, C. T. (2016) How Many Carbonic Anhydrase Inhibition Mechanisms Exist?, Journal of Enzyme Inhibition and Medicinal Chemistry 31, 345-360.

72. Métayer, B., Martin-Mingot, A., Vullo, D., Supuran, C. T., and Thibaudeau, S. (2013) Superacid Synthesized Tertiary Benzenesulfonamides and Benzofuzed Sultams Act as Selective hCA IX Inhibitors: Toward Understanding a New Mode of Inhibition by Tertiary Sulfonamides, Organic \& Biomolecular Chemistry 11, 7540-7549.

73. Dekaminavičiūtè, D., Kairys, V., Zilnytė, M., Petrikaitė, V., Jogaite, V., Matulienė, J., Gudlevičienè, Z., Vullo, D., Supuran, C. T., and Žvirbliené, A. (2014) Monoclonal Antibodies Raised against 167-180 Aa Sequence of Human Carbonic Anhydrase XII Inhibit Its Enzymatic Activity, Journal of Enzyme Inhibition and Medicinal Chemistry 29, 804-810.

74. Dudutienè, V., Matulienè, J., Smirnov, A., Timm, D. D., Zubrienè, A., Baranauskienė, L., Morkūnaite, V., Smirnovienė, J., Michailovienė, V., Juozapaitienė, V., Mickevičiūtė, A., Kazokaite, J., Bakšytė, S., Kasiliauskaitė, A., Jachno, J., Revuckienė, J., Kišonaitė, M., Pilipuitytė, V., Ivanauskaitė, E., Milinavičiūtė, G., Smirnovas, V., Petrikaitė, V., Kairys, V., Petrauskas, V., Norvaišas, P., Lingė, D., Gibieža, P., Čapkauskaite, E., Zakšauskas, A., Kazlauskas, E., Manakova, E., Gražulis, S., Ladbury, J. E., and Matulis, D. (2014) Discovery and Characterization of Novel Selective Inhibitors of Carbonic Anhydrase IX, Journal of Medicinal Chemistry 57, 9435-9446.

75. Tashian, R. E., Douglas, D. P., and Yu, Y. S. (1964) Esterase and Hydrase Activity of Carbonic Anhydrase. I. From Primate Erythrocytes, Biochemical and Biophysical Research Communications 14, 256-261.

76. Akıncıoğlu, A., Akbaba, Y., Göçer, H., Göksu, S., Gülçin, İ., Supuran, C.T. (2013) Novel Sulfamides as Potential Carbonic Anhydrase Isoenzymes Inhibitors, Bioorganic \& Medicinal Chemistry 21, 1379-1385.

77. Uda, N. R., Seibert, V., Stenner-Liewen, F., Müller, P., Herzig, P., Gondi, G., Zeidler, R., Dijk, M. van, Zippelius, A., and Renner, C. (2015) Esterase Activity of Carbonic Anhydrases Serves as Surrogate for Selecting Antibodies Blocking Hydratase Activity, Journal of Enzyme Inhibition and Medicinal Chemistry 30, 955-960.

78. Smirnoviené, J., Smirnovas, V., and Matulis, D. (2017) Picomolar Inhibitors of Carbonic Anhydrase: Importance of Inhibition and Binding Assays, Analytical Biochemistry 522, 61-72.

79. Izatt, R. M., Rytting, J. H., Hansen, L. D., and Christensen, J. J. (1966) Thermodynamics of Proton Dissociation in Dilute Aqueous Solution. V. An Entropy Titration Study of Adenosine, Pentoses, Hexoses, and Related Compounds1a,B, Journal of the American Chemical Society 88, 2641-2645.

80. Christensen, J. J., Izatt, R. M., Hansen, L. D., and Partridge, J. A. (1966) Entropy Titration. A Calorimetric Method for the Determination of $\Delta \mathrm{G}, \Delta \mathrm{H}$, and $\Delta \mathrm{S}$ from a Single Thermometric Titration1a,B, The Journal of Physical Chemistry 70, $2003-2010$.

81. Ramsay, G., Prabhu, R., and Freire, E. (1986) Direct Measurement of the Energetics of Association between Myelin Basic Protein and Phosphatidylserine Vesicles, Biochemistry 25, 2265-2270.

82. Schön, A., and Freire, E. (1989) Thermodynamics of Intersubunit Interactions in Cholera Toxin upon Binding to the Oligosaccharide Portion of Its Cell Surface Receptor, Ganglioside GM1, Biochemistry 28, 5019-5024.

83. Klebe, G. (2015) Applying Thermodynamic Profiling in Lead Finding and Optimization, Nature Reviews Drug Discovery 14, 95-110.

84. Krimmer, S. G., and Klebe, G. (2015) Thermodynamics of Protein-ligand Interactions as a Reference for Computational Analysis: How to Assess Accuracy, Reliability and Relevance of Experimental Data, Journal of Computer-Aided Molecular Design 29, 867 883.

85. Geschwindner, S., Ulander, J., and Johansson, P. (2015) Ligand Binding Thermodynamics in Drug Discovery: Still a Hot Tip?, Journal of Medicinal Chemistry 58,6321-6335.

86. Falconer, R. J. (2016) Applications of Isothermal Titration Calorimetry - the Research and Technical Developments from 2011 to 2015, Journal of molecular recognition: JMR.

87. DiTusa, C. A., Christensen, T., McCall, K. A., Fierke, C. A., and Toone, E. J. (2001) Thermodynamics of Metal Ion Binding. 1. Metal Ion Binding by Wild-Type Carbonic Anhydrase, Biochemistry 40, 5338-5344.

88. Khalifah, R. G., Zhang, F., Parr, J. S., and Rowe, E. S. (1993) Thermodynamics of Binding of the CO2-Competitive Inhibitor Imidazole and Related Compounds to Human Carbonic Anhydrase I: An Isothermal Titration Calorimetry Approach to Studying Weak Binding by Displacement with Strong Inhibitors, Biochemistry 32, 3058-3066.

89. Fox, J. M., Kang, K., Sherman, W., Héroux, A., Sastry, G. M., Baghbanzadeh, M., Lockett, M. R., and Whitesides, G. M. (2015) Interactions between Hofmeister Anions and the Binding Pocket of a Protein, Journal of the American Chemical Society 137, 38593866 . 


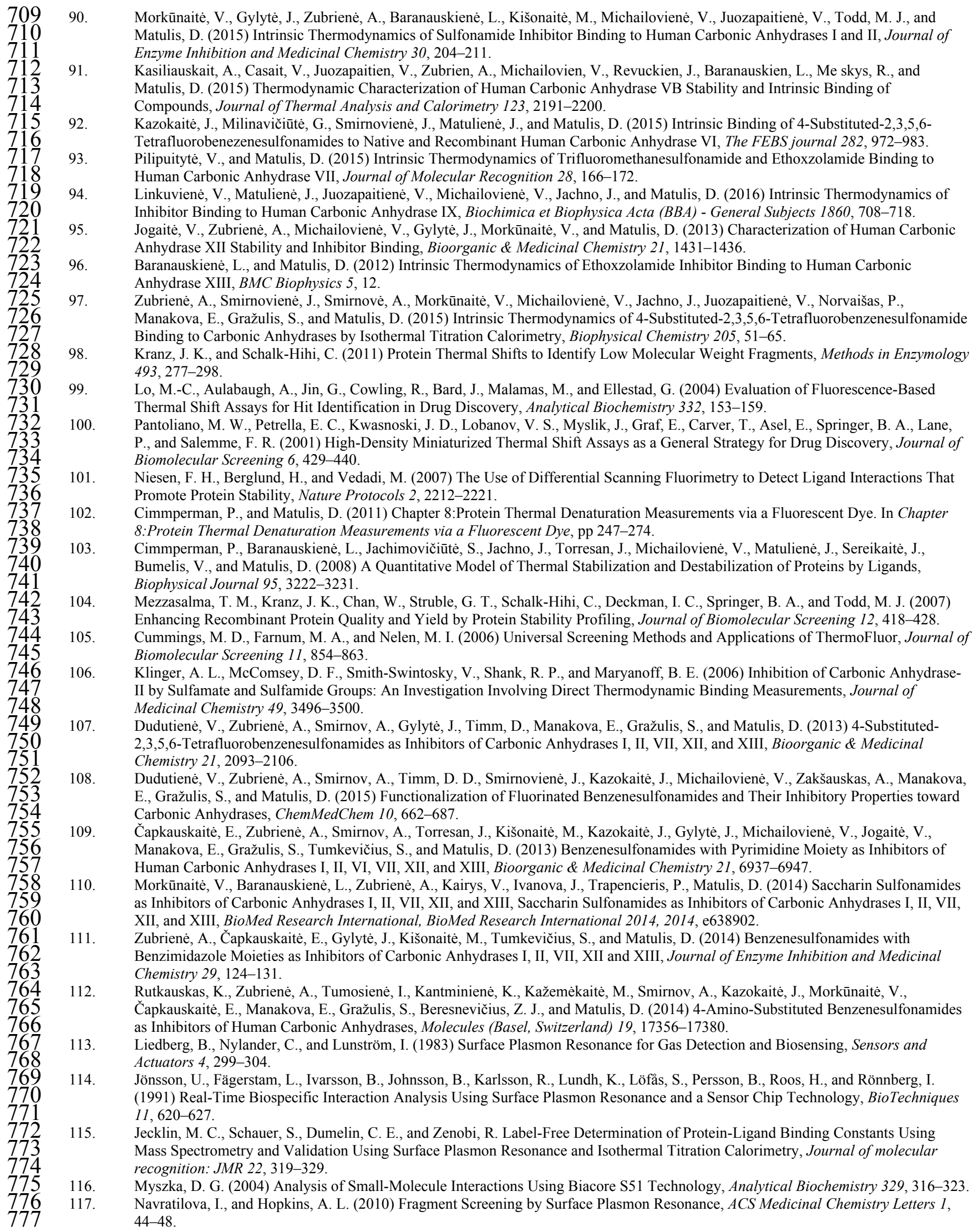


118. Papalia, G. A., Leavitt, S., Bynum, M. A., Katsamba, P. S., Wilton, R., Qiu, H., Steukers, M., Wang, S., Bindu, L., Phogat, S., Giannetti, A. M., Ryan, T. E., Pudlak, V. A., Matusiewicz, K., Michelson, K. M., Nowakowski, A., Pham-Baginski, A., Brooks, J., Tieman, B. C., Bruce, B. D., Vaughn, M., Baksh, M., Cho, Y. H., Wit, M. D., Smets, A., Vandersmissen, J., Michiels, L., and Myszka, D. G. (2006) Comparative Analysis of 10 Small Molecules Binding to Carbonic Anhydrase II by Different Investigators Using Biacore Technology, Analytical Biochemistry 359, 94-105.

119. Talibov, V. O., Linkuviene, V., Matulis, D., and Danielson, U. H. (2016) Kinetically Selective Inhibitors of Human Carbonic Anhydrase Isozymes I, II, VII, IX, XII, and XIII, Journal of Medicinal Chemistry.

120. MacRae, C. A., and Peterson, R. T. (2015) Zebrafish as Tools for Drug Discovery, Nature Reviews Drug Discovery 14, 721-731.

121. Lin, C.-Y., Chiang, C.-Y., and Tsai, H.-J. (2016) Zebrafish and Medaka: New Model Organisms for Modern Biomedical Research, Journal of Biomedical Science 23, 19.

122. Rennekamp, A. J., and Peterson, R. T. (2015) 15 Years of Zebrafish Chemical Screening, Current Opinion in Chemical Biology 24, $58-70$.

123. Kazokaite, J., Aspatwar, A., Kairys, V., Parkkila, S., and Matulis, D. (2016) Fluorinated Benzenesulfonamide Anticancer Inhibitors of Carbonic Anhydrase IX Exhibit Lower Toxic Effects on Zebrafish Embryonic Development than Ethoxzolamide, Drug and Chemical Toxicology 1-11.

124. Becker, H. (2014) Transport of Lactate: Characterization of the Transporters Involved in Transport at the Plasma Membrane by Heterologous Protein Expression in Xenopus Oocytes. In Brain Energy Metabolism (Hirrlinger, J., and Waagepetersen, H. S., Eds.), pp 25-43, Springer New York.

125. Klier, M., Jamali, S., Ames, S., Schneider, H.-P., Becker, H. M., and Deitmer, J. W. (2016) Catalytic Activity of Human Carbonic Anhydrase Isoform IX Is Displayed Both Extra- and Intracellularly, FEBS Journal 283, 191-200.

126. Schneider, H.-P., Alt, M. D., Klier, M., Spiess, A., Andes, F. T., Waheed, A., Sly, W. S., Becker, H. M., and Deitmer, J. W. (2013) GPI-Anchored Carbonic Anhydrase IV Displays Both Intra- and Extracellular Activity in cRNA-Injected Oocytes and in Mouse Neurons, Proceedings of the National Academy of Sciences 110, 1494-1499.

127. Kazokaite, J., Ames, S., Becker, H. M., Deitmer, J. W., and Matulis, D. (2016) Selective Inhibition of Human Carbonic Anhydrase IX in Xenopus Oocytes and MDA-MB-231 Breast Cancer Cells, Journal of Enzyme Inhibition and Medicinal Chemistry 1-7.

128. Oosterwijk, E., Ruiter, D. J., Hoedemaeker, P. J., Pauwels, E. K., Jonas, U., Zwartendijk, J., and Warnaar, S. O. (1986) Monoclonal Antibody G 250 Recognizes a Determinant Present in Renal-Cell Carcinoma and Absent from Normal Kidney, International Journal of Cancer 38, 489-494.

129. Závada, J., Závadová, Z., Pastoreková, S., Ciampor, F., Pastorek, J., and Zelnık, V. (1993) Expression of MaTu-MN Protein in Human Tumor Cultures and in Clinical Specimens, International Journal of Cancer 54, 268-274.

130. Chrastina, A., Pastoreková, S., and Pastorek, J. (2003) Immunotargeting of Human Cervical Carcinoma Xenograft Expressing CA IX Tumor-Associated Antigen by 125I-Labeled M75 Monoclonal Antibody, Neoplasma 50, 13-21.

131. Chrastina, A., Závada, J., Parkkila, S., Kaluz, S., Kaluzová, M., Raj cáni, J., Pastorek, J., and Pastoreková, S. (2003) Biodistribution and Pharmacokinetics of 125I-Labeled Monoclonal Antibody M75 Specific for Carbonic Anhydrase IX, an Intrinsic Marker of Hypoxia, in Nude Mice Xenografted with Human Colorectal Carcinoma, International Journal of Cancer 105, 873-881.

132. Zatovicova, M., Jelenska, L., Hulikova, A., Csaderova, L., Ditte, Z., Ditte, P., Goliasova, T., Pastorek, J., and Pastorekova, S. (2010) Carbonic Anhydrase IX as an Anticancer Therapy Target: Preclinical Evaluation of Internalizing Monoclonal Antibody Directed to Catalytic Domain, Current Pharmaceutical Design 16, 3255-3263.

133. Cardone, R. A., Casavola, V., and Reshkin, S. J. (2005) The Role of Disturbed pH Dynamics and the Na+/H+ Exchanger in Metastasis, Nature Reviews. Cancer 5, 786-795.

134. Surfus, J. E., Hank, J. A., Oosterwijk, E., Welt, S., Lindstrom, M. J., Albertini, M. R., Schiller, J. H., and Sondel, P. M. (1996) AntiRenal-Cell Carcinoma Chimeric Antibody G250 Facilitates Antibody-Dependent Cellular Cytotoxicity with in Vitro and in Vivo Interleukin-2-Activated Effectors, Journal of Immunotherapy with Emphasis on Tumor Immunology: Official Journal of the Society for Biological Therapy 19, 184-191.

135. Davis, I. D., Wiseman, G. A., Lee, F.-T., Gansen, D. N., Hopkins, W., Papenfuss, A. T., Liu, Z., Moynihan, T. J., Croghan, G. A., Adjei, A. A., Hoffman, E. W., Ingle, J. N., Old, L. J., and Scott, A. M. (2007) A Phase I Multiple Dose, Dose Escalation Study of cG250 Monoclonal Antibody in Patients with Advanced Renal Cell Carcinoma, Cancer Immunity 7, 13.

136. Siebels, M., Rohrmann, K., Oberneder, R., Stahler, M., Haseke, N., Beck, J., Hofmann, R., Kindler, M., Kloepfer, P., and Stief, C. (2011) A Clinical Phase I/II Trial with the Monoclonal Antibody cG250 (RENCAREX®) and Interferon-Alpha-2a in Metastatic Renal Cell Carcinoma Patients, World Journal of Urology 29, 121-126.

137. McDonald, P. C., Winum, J.-Y., Supuran, C. T., and Dedhar, S. (2012) Recent Developments in Targeting Carbonic Anhydrase IX for Cancer Therapeutics, Oncotarget 3, 84-97.

138. A Randomized, Double Blind Phase III Study to Evaluate Adjuvant cG250 Treatment Versus Placebo in Patents with Clear Cell RCC and High Risk of Recurrence (ARISER). Available online:

https://clinicaltrials.gov/ct2/show/NCT00087022?term=girentuximab\&rank=6 (accessed on 17 October 2017)

139. Pal, S. K., and Agarwal, N. (2016) Kidney Cancer: Finding a Niche for Girentuximab in Metastatic Renal Cell Carcinoma, Nature Reviews. Urology 13, 442-443.

140. Wilex, Focused Cencer Therapies. Pipeline of Proprietary and Partnered Programs, Half-yearly report 2017, Page 1-24. Available online: http://www.wilex.de/wp-content/uploads/2015/01/20170713_WILEX_Press_Analyst_Presentation_6M-2017_final.pdf (accessed on 17 October 2017)

141. Zat’ovicová, M., Tarábková, K., Svastová, E., Gibadulinová, A., Mucha, V., Jakubıcková, L., Biesová, Z., Rafajová, M., Ortova Gut, M., Parkkila, S., Parkkila, A. K., Waheed, A., Sly, W. S., Horak, I., Pastorek, J., and Pastoreková, S. (2003) Monoclonal Antibodies Generated in Carbonic Anhydrase IX-Deficient Mice Recognize Different Domains of Tumour-Associated Hypoxia-Induced Carbonic Anhydrase IX, Journal of Immunological Methods 282, 117-134.

142. Zatovicova, M., Jelenska, L., Hulikova, A., Csaderova, L., Ditte, Z., Ditte, P., Goliasova, T., Pastorek, J., and Pastorekova, S. (2010) Carbonic Anhydrase IX as an Anticancer Therapy Target: Preclinical Evaluation of Internalizing Monoclonal Antibody Directed to Catalytic Domain, Current Pharmaceutical Design 16, 3255-3263.

143. Xu, S. (2015) Internalization, Trafficking, Intracellular Processing and Actions of Antibody-Drug Conjugates, Pharmaceutical Research 32, 3577-3583. 


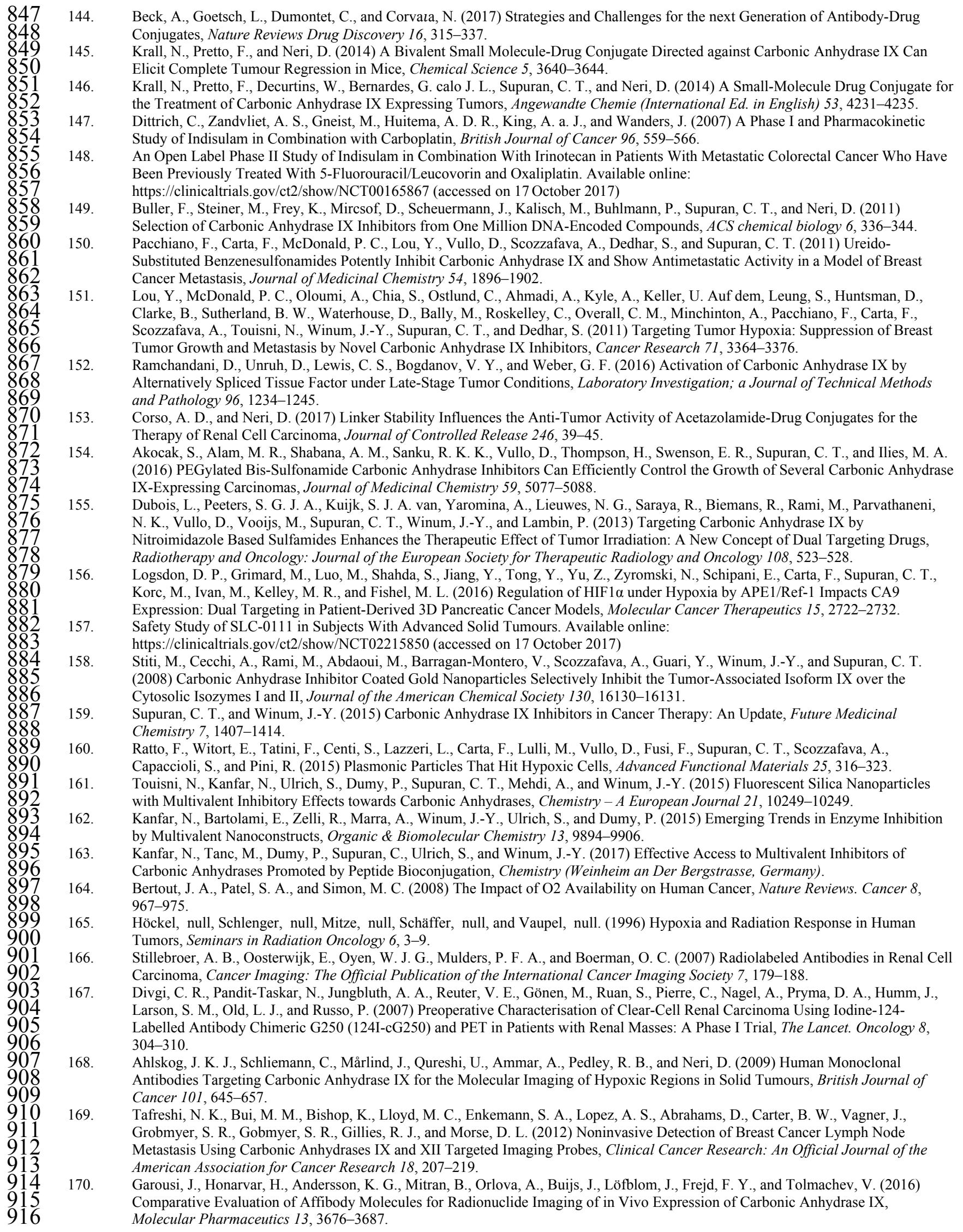


171. Svastová, E., Hulıková, A., Rafajová, M., Zat’ovicová, M., Gibadulinová, A., Casini, A., Cecchi, A., Scozzafava, A., Supuran, C. T., Pastorek, J., and Pastoreková, S. (2004) Hypoxia Activates the Capacity of Tumor-Associated Carbonic Anhydrase IX to Acidify Extracellular pH, FEBS letters 577, 439-445.

172. Pastorekova, S., Ratcliffe, P. J., and Pastorek, J. (2008) Molecular Mechanisms of Carbonic Anhydrase IX-Mediated pH Regulation under Hypoxia, BJU international 101 Suppl 4, 8-15.

173. Li, Y., Wang, H., Oosterwijk, E., Selman, Y., Mira, J. C., Medrano, T., Shiverick, K. T., and Frost, S. C. (2009) Antibody-Specific Detection of CAIX in Breast and Prostate Cancers, Biochemical and Biophysical Research Communications 386, 488-492.

174. Groves, K., Bao, B., Zhang, J., Handy, E., Kennedy, P., Cuneo, G., Supuran, C. T., Yared, W., Peterson, J. D., and Rajopadhye, M. (2012) Synthesis and Evaluation of Near-Infrared Fluorescent Sulfonamide Derivatives for Imaging of Hypoxia-Induced Carbonic Anhydrase IX Expression in Tumors, Bioorganic \& Medicinal Chemistry Letters 22, 653-657.

175. Cecchi, A., Hulikova, A., Pastorek, J., Pastoreková, S., Scozzafava, A., Winum, J.-Y., Montero, J.-L., and Supuran, C. T. (2005) Carbonic Anhydrase Inhibitors. Design of Fluorescent Sulfonamides as Probes of Tumor-Associated Carbonic Anhydrase IX That Inhibit Isozyme IX-Mediated Acidification of Hypoxic Tumors, Journal of Medicinal Chemistry 48, 4834-4841.

176. Ahlskog, J. K. J., Dumelin, C. E., Trüssel, S., Mårlind, J., and Neri, D. (2009) In Vivo Targeting of Tumor-Associated Carbonic Anhydrases Using Acetazolamide Derivatives, Bioorganic \& Medicinal Chemistry Letters 19, 4851-4856.

177. Lv, P.-C., Putt, K. S., and Low, P. S. (2016) Evaluation of Nonpeptidic Ligand Conjugates for SPECT Imaging of Hypoxic and Carbonic Anhydrase IX-Expressing Cancers, Bioconjugate Chemistry 27, 1762-1769. 


\section{Figure 1}

\section{Methods}

Methods which might be applied for developing CA IX-targeting compounds before pre-

clinical characterization in tumor cells and mice

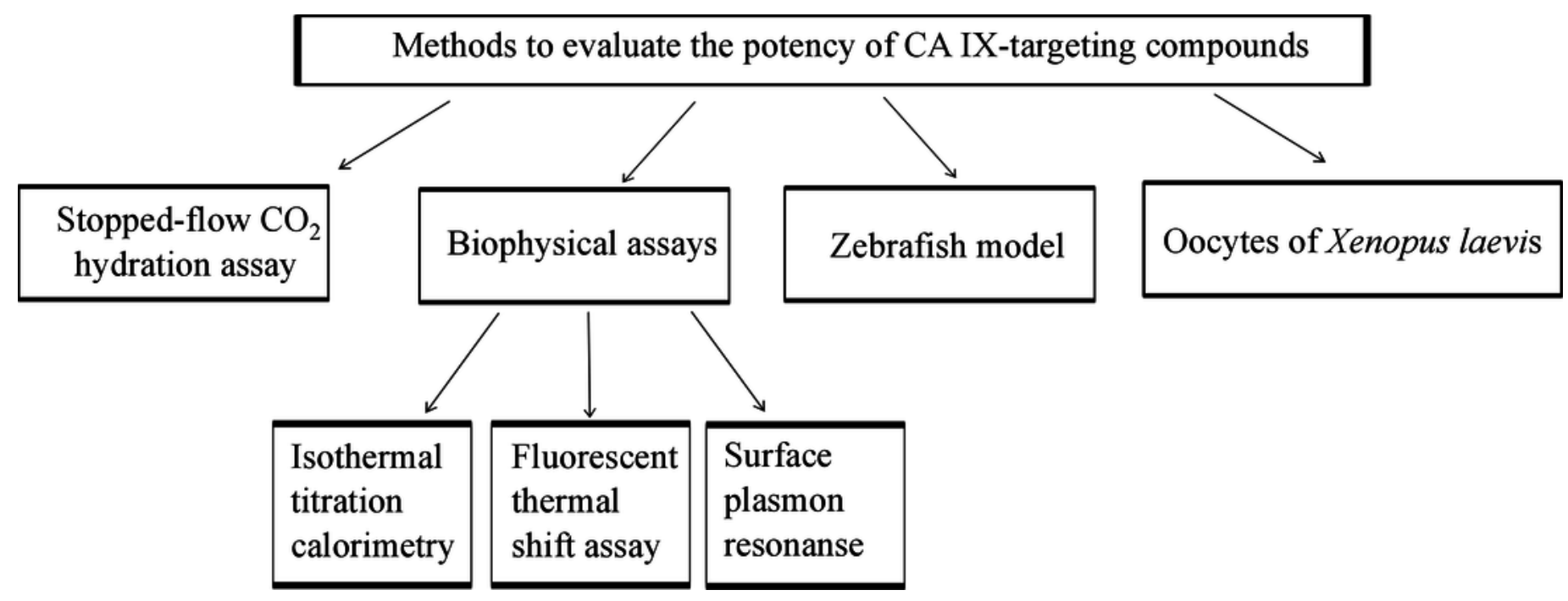




\section{Table $\mathbf{1}$ (on next page)}

Biological model systems for the investigation of CA IX inhibitors

The compounds did not show any significant toxicity on zebrafish and possessed nanomolar $I C_{50}$ for heterologous CA IX expressed in Xenopus oocytes. In addition, the selectivity of compounds toward CA isoforms was evaluated according to the effect of compounds on the reduction of extracellular (CA IX, CA IV, and CA XII) and intracellular (CA II) CA-induced acidification in oocytes [123, 127]. 
1 Table 1. Biological model systems for the investigation of CA IX inhibitors. The compounds did 2 not show any significant toxicity on zebrafish and possessed nanomolar $I C_{50}$ for heterologous 3 CA IX expressed in Xenopus oocytes. In addition, the selectivity of compounds toward CA 4 isoforms was evaluated according to the effect of compounds on the reduction of extracellular 5 (CA IX, CA IV, and CA XII) and intracellular (CA II) CA-induced acidification in oocytes [119, $6 \quad 123]$.

7

\begin{tabular}{|l|l|l|}
\hline Type of study & $L C_{50}=120 \mu \mathrm{M}$ \\
\hline Toxicology & Methods: \\
1. & light-field microscopy \\
2. & histological analysis
\end{tabular}

$8 I C_{50}$ - the concentration causing $50 \%$ inhibition of target activity, $L C_{50}-50 \%$ lethal concentration. 


\section{Table 2 (on next page)}

Anti-tumor agents for targeting hypoxia-induced CA IX for therapy and diagnosis 
1 Table 2. Anti-tumor agents for targeting hypoxia-induced CA IX for therapy and diagnosis 2

\begin{tabular}{|c|c|c|c|}
\hline Anti-tumor agents & Therapy stage & Diagnosis & References \\
\hline SLC-0111 & Phase I trial & Solid tumors & {$[157]$} \\
\hline U-104 & $\begin{array}{l}\text { Preclinical } \\
\text { trials }\end{array}$ & $\begin{array}{l}\text { Xenograft tumor model } \\
\text { (pancreatic } \\
\text { adenocarcinoma cell line } \\
\text { Pt45.P1/asTF+) }\end{array}$ & {$[150-152]$} \\
\hline $\begin{array}{c}\mathrm{G} 250 \\
\text { (girentuximab) }\end{array}$ & $\begin{array}{l}\text { Phase III } \\
\text { clinical trial }\end{array}$ & ccRCC diagnosis & {$[138]$} \\
\hline${ }^{177} \mathrm{Lu}$-labelled girentuximab & $\begin{array}{l}\text { Phase II } \\
\text { clinical trials }\end{array}$ & ccRCC diagnosis & [139] \\
\hline Indisulam & $\begin{array}{l}\text { Phase I clinical } \\
\text { trials }\end{array}$ & Solid tumors & {$[147,148]$} \\
\hline $\begin{array}{l}\text { NIR fluorescent derivative of } \\
\text { the acetazolamide }\end{array}$ & $\begin{array}{l}\text { Preclinical } \\
\text { trials }\end{array}$ & Xenograft tumor model & [169] \\
\hline 99mTc-(HE)3-ZCAIX:2 & $\begin{array}{l}\text { Preclinical } \\
\text { trials }\end{array}$ & Disseminated cancer & {$[170]$} \\
\hline${ }^{125}$ I-ZCAIX:4 & $\begin{array}{l}\text { Preclinical } \\
\text { trials }\end{array}$ & $\begin{array}{lll}\begin{array}{l}\text { Primary } \\
\text { carcinoma }\end{array} & \text { renal } & \text { cell }\end{array}$ & {$[170]$} \\
\hline
\end{tabular}

